\title{
Predictors of employment for people with severe mental illness: results of an international six-centre randomised controlled trial
}

Jocelyn Catty, Pascale Lissouba, Sarah White, Thomas Becker, Robert E. Drake, Angelo Fioritti, Martin Knapp, Christoph Lauber, Wulf Rössler, Toma Tomov, Jooske van Busschbach, Durk Wiersma and Tom Burns, on behalf of the EQOLISE Group

\section{Background}

An international six-centre randomised controlled trial comparing individual placement and support (IPS) with usual vocational rehabilitation for people with serious mental illness found IPS to be more effective for all vocational outcomes.

\section{Aims \\ To determine which patients with severe mental illness do well in vocational services and which process and service factors are associated with better outcomes. \\ Method \\ Patient characteristics and early process variables were tested as predictors of employment outcomes. Service characteristics were explored as predictors of the effectiveness of IPS.}

\section{Results}

Patients with previous work history, fewer met social needs and better relationships with their vocational workers were more likely to obtain employment and work for longer. Remission and swifter service uptake were associated with working more. Having an IPS service closer to the original IPS model was the only service characteristic associated with greater effectiveness.

\section{Conclusions}

The IPS service was found to be more effective for all vocational outcomes. In addition, maintaining high IPS fidelity and targeting relational skills would be a valuable focus for all vocational interventions, leading to improved employment outcomes. Motivation to find work may be decreased by satisfaction with current life circumstances.

\section{Declaration of interest}

None. Funding detailed in Acknowledgements.
In Europe, employment rates of between $10 \%$ and $20 \%$ are reported for people with schizophrenia, ${ }^{1}$ yet people with severe mental illness want to work. ${ }^{2}$ The effectiveness of the individual placement and support (IPS) model of supported employment at increasing this group's access to work has been demonstrated in North America. ${ }^{3-6}$ Its effectiveness in European contexts has also been demonstrated by a recent six-centre randomised controlled trial, which found that IPS doubled patients' access to work. ${ }^{7}$ Patients with schizophrenia and those with less prior experience have been found to be less likely to obtain work, ${ }^{8}$ but the validity of these findings for the IPS model and in Europe has not been established. The impact of service and 'process' characteristics has never been tested.

We aimed to explore who among a group of patients with severe mental illness would do well in vocational services in terms of both obtaining and maintaining open, competitive employment, and which process and service factors would be associated with better outcomes. We therefore aimed to determine predictors of employment outcomes from among demographic and illness characteristics, early process factors and service features.

\section{Method}

\section{Sample, setting and procedure}

A randomised controlled trial was conducted in six European centres - London, Ulm-Günzburg, Rimini, Zurich, Groningen and Sofia - comparing IPS with usual high-quality vocational rehabilitation based on the 'train and place' model. Individual placement and support workers were trained for the study by the originator of the model and supervised centrally by a fortnightly telephone conference. The vocational service (control service) at each centre was the best alternative vocational rehabilitation service available locally, with a structured programme conducted mostly in day facilities (although mostly residential in Ulm). Each had to guarantee taking patients into the service within 2 months of randomisation.

Patients $(n=312)$ were recruited if they had psychotic illness, were aged between 18 and the local retirement age, had been ill and had major role dysfunction for at least 2 years, were in the community, had not been in competitive employment in the preceding year and wanted to enter competitive employment. Randomisation was carried out centrally and stratified by centre, gender and work history ( 1 month or less of continuous open employment $v$. more than 1 month in the previous 5 years), replicating the original IPS study. ${ }^{3}$

Patients were followed up for 18 months, with interviews at baseline $\left(T_{0}\right)$ and 6,12 and 18 months $\left(T_{1}-T_{3}\right)$. Data were collected through interview on:

(a) vocational outcomes

(b) hospitalisation

(c) global functioning (Global Assessment of Functioning Symptoms (GAF-S) and Disability (GAF-D) $)^{9}$

(d) symptoms (Positive and Negative Syndrome Scale; PANSS) ${ }^{10}$

(e) anxiety and depression (Hospital Anxiety and Depression Scale; HADS) ${ }^{11}$

(f) social disability (Groningen Social Disability Schedule; GSDS) $)^{12,13}$ 
(g) quality of life (Lancashire Quality of Life Profile - European Version; LQoLP-EU) $)^{14,15}$

(h) self-esteem (Rosenberg Self-Esteem Scale; RSE) ${ }^{16}$

(i) needs for care (Camberwell Assessment of Need - European short version; CAN-EU). ${ }^{17,18}$

Patients were also asked about the therapeutic relationship with their clinical keyworker or equivalent, using a measure (Helping Alliance Scale; HAS) ${ }^{19}$ developed for community psychiatric patients (HAS-k), at baseline and each follow-up interview. They were also asked about the relationship with their vocational worker (IPS worker or named worker in the vocational service; HAS-v) at each follow-up interview. Job status was collected regularly from vocational staff, while data on therapeutic relationships (HAS) were collected from them using a modified version of HAS (HAS-p) at each follow-up point. Clinical diagnosis was confirmed by OPCRIT. ${ }^{20}$ The fidelity to the IPS model of both the IPS and the vocational services was assessed using the IPS fidelity scale ${ }^{21}$ at three time-points; further service characteristics were also collected at two time-points.

Being in remission was also tested. Patients were defined as being in remission if they met van Os et al's ${ }^{22}$ criteria: that symptoms measured by PANSS (delusions, unusual thought content, hallucinatory behaviour, conceptual disorganisation, mannerism/ posturing, blunted affect, passive/apathetic social withdrawal and lack of spontaneity and flow of conversation) were rated as absent, minimal or mild for a 6-month period (i.e. at two consecutive time-points).

The study's primary outcome was entering competitive employment (on the open market, paid at prevailing wages), operationalised as working for at least 1 day over the entire follow-up period, in replication of the original study. ${ }^{3}$ Secondary vocational outcomes were the number of hours worked and the number of days employed (regardless of hours worked per week), all on an 'intention to treat' basis. For patients employed at any point during follow-up, job tenure (duration of longest job) was examined (presented separately below). For the present analyses, hours worked and days employed were found to be highly correlated (Spearman's rho $=0.78$ ), so days employed was not further analysed.

\section{Statistical analyses}

Three analyses were conducted. First, patient characteristics collected at baseline, including illness characteristics and the patient's reported relationship with their clinical keyworker, were tested as potential predictors of the employment outcomes. Second, early process factors, collected at patient level at the first follow-up interview $\left(T_{1}\right)$, when the patient had been in the service for up to 6 months, were tested as potential predictors. Service allocation (IPS $v$. vocational service) was included as a possible explanatory variable in the early process models, despite the fact that the greater effectiveness of the IPS service had already been demonstrated. ${ }^{7}$ This was to ensure that it was not confounding any significant associations between other potential predictor variables and employment outcomes. It was not included in the patient characteristics models, as these variables were measured before randomisation. The impact of service as such is not the focus of the current paper. Finally, key characteristics of the services themselves were tested. As the latter were service-level factors, they were tested against the effectiveness of the IPS service at each international centre.

\section{Patient characteristic predictors}

A logistic regression analysis was conducted to determine patient characteristics predictive of entering competitive employment (working for at least 1 day). This was preceded by univariate analysis of baseline demographic, clinical and social functioning data based on evidence from the literature of factors that have a potential impact on employment outcomes. These included:

\section{(a) age}

(b) gender

(c) diagnosis (schizophrenia $v$. bipolar disorder)

(d) age at first contact with psychiatric services

(e) number of lifetime psychiatric admissions

(f) living situation

(g) immigrant status

(h) years of education

(i) prior work history and baseline global functioning (GAF-S, GAF-D)

(j) anxiety and depression (HADS-A and HADS-D respectively)

(k) symptoms (PANSS positive, negative and general scores)

(l) social disability (GSDS sub-scales and total score)

(m) quality of life (LQoLP sub-scales and total score)

(n) needs (CAN total number of needs, number of met needs and proportion of needs met for all five CAN sub-scales and the CAN total score)

(o) self-esteem (RSE).

Remission between baseline and $T_{1}$ and baseline therapeutic relationship with the clinical keyworker (HAS-k) were also tested. Univariate associations were analysed using $\chi^{2}$-tests for categorical predictors and unpaired $t$-tests for continuous predictors.

Variables significant at the $10 \%$ level were entered into the logistic regression. These analyses were carried out using SPSS for Windows version 14 . Regression analyses modelling the number of hours worked and job tenure (employed patients only) against the potential predictors listed above were conducted using methods appropriate for count data. ${ }^{23}$ Zero-inflated Poisson regression, which is a mixture of a Poisson distribution and a degenerate distribution with point mass one at zero, ${ }^{24}$ was used for hours worked as this displayed a large frequency of zeros $(59.0 \%$ of the data). Job tenure $(n=122)$ was modelled using regression methods for over-dispersed Poisson-distributed data. For both outcomes, predictor variables univariately significant at the $10 \%$ level were then entered into a multivariate model. These analyses were performed with SAS for Windows Version 9.1, using PROC NLMIXED for the zero-inflated Poisson-distributed outcomes and PROC GENMOD for job tenure.

\section{Early process predictors}

Potential early process predictors of entering employment, hours worked and job tenure included the following variables at $T_{1}$ (the earliest point at which these could be measured): IPS/vocational service; number of meetings with the IPS/vocational worker; whether the patient received vocational training; patient-rated therapeutic relationship with the vocational worker (HAS-v); and vocational worker-rated therapeutic relationship with the patient (HAS-p). Time from baseline to entry into the service $(0-2$ months, 2-6 months and not in service at 6 months, or never taken into service) was also included as, despite the stipulation that this should be no more than 2 months, many patients were taken into the service much later. These potential explanatory 
variables were selected by a priori discussion in the research group. A regression model was fitted to investigate whether these variables at $T_{1}$ predicted the vocational outcomes after the appropriate univariate analyses. Patients who had not entered the service by 6 months would not have a vocational worker and were therefore excluded from the analyses, as their inclusion would create a non-random missing-value pattern for the patient- and professional-rated therapeutic relationship scores. Time to service entry was therefore also analysed univariately. The regression models were repeated without the variable IPS/vocational service, as this was known to be a powerful predictor of employment.

\section{Service characteristic predictors of IPS effectiveness}

Whether the greater effectiveness of the IPS service at some international centres was related to differences in their vocational services was explored using prospective meta-analyis. The dependent variable was the risk difference in the primary outcome (worked for at least 1 day) between IPS and vocational service groups for each centre (IPS effect sizes). The heterogeneity found was modelled using five centre-level service characteristics, chosen a priori. Each of these factors was a contrast between the IPS and vocational service in that centre. They comprised: the contrast in IPS fidelity between the IPS and vocational services; the difference in the proportion of patients entering the service within 2 months; the contrast in whether the services operated a named keyworker system or not; the difference in case-load size; and the contrast in whether the service required its patients to undertake particular steps before seeking employment.

Meta-analytic methods were used to explore the relationship between categorical variables and IPS effect size, and meta-regression methods for continuous variables, using Comprehensive MetaAnalysis Version 2.

\section{Results}

\section{Sample}

A total of 1036 people were referred to the study, of whom 728 participated in information meetings and 312 were recruited. Data on the primary outcome measure (entered competitive employment) were obtained for the whole sample. Of these, 252 $(80.8 \%)$ completed the final follow-up interview. There were no differences between those who did not complete the final interview and those who stayed in the study in terms of baseline characteristics or withdrawal from IPS/vocational service. Details previously reported. ${ }^{7}$

The majority of the sample had a diagnosis of schizophrenia $(80.3 \%)$ and were male $(60.3 \%) ; 55.8 \%$ had worked for more than 1 month in the previous 5 years. ${ }^{7}$ The mean levels of global symptomatology and disability (GAF-S and GAF-D) were 55.3 and 53.8 (out of 100) respectively, ranging from 20 to 80 . Positive, negative and general symptoms (as measured by PANSS) were 13.4 (range 7-33), 15.1 (range 7-35) and 31.3 (range 16-67) respectively, and levels of anxiety and depression (HADS) were 6.8 (range 0-19) and 6.2 (range 0-19) respectively. Social disability (GSDS) was moderate at 9.1 out of 21 (range 1-21); overall subjective quality of life (LQoLP) was 4.4 out of 7 (range 2.28-6.67); the level of need (CAN) was 6.0 out of 22 (range $0-16)$ and the proportion of needs rated as met was $67 \%(0-100)$.

The IPS services were more effective than the vocational services for every vocational outcome, with 85 IPS patients (54.5\%) working for at least 1 day compared with 43 vocational service patients $(27.6 \%)$ and IPS patients working for nearly four times as many hours (428.8 v. 119.1) over the 18-month follow-up period. Of those who worked, the duration of the longest held job was twice as long for IPS patients (214 days) as for vocational service patients (108 days). ${ }^{7}$

Of the 128 clients who worked, only 2 from each service had only worked for 1 day (the minimum threshold used for the primary outcome measure) and 95 had worked for more than 40 days. Just over half the IPS patients who worked $(n=48$; $56.5 \%$ ) obtained the job before their $T_{1}$ interview, compared with 16 vocational service clients $(37.2 \%)$.

\section{Patient-level predictors}

\section{Patient characteristics as predictors of entering competitive} employment

An association with having worked for at least 1 day at the level appropriate for inclusion in the logistic regression $(P<0.1)$ was found for clinical diagnosis, work history, global disability, depression, satisfaction with job situation, satisfaction with financial situation, number of assessed social needs, proportion of social needs met and remission status. Logistic regression yielded a model in which previous work history and proportion of social needs met were significant predictors of entering employment (Table 1). Patients who had worked for more than 1 month in the 5 years prior to baseline were more than twice as likely to enter employment as patients who had not $(\mathrm{OR}=2.42$, 95\% CI $1.46-$ 4.02 ), and a 33 percentage point decrease in social needs met (one fewer social need being met out of three) was associated with a $33 \%$ higher probability of working for at least 1 day $(\mathrm{OR}=0.99$, 95\% CI 0.98-1.00).

As remission was measured at $T_{1}$ (patients had to meet the clinical criteria at both baseline and $T_{1}$ ), by which time some patients had already entered employment, a sensitivity analysis was conducted excluding data from patients who entered employment before $T_{1}$. Remission was not associated with entering employment in this analysis.

\section{Patient characteristics as predictors of time worked}

Significant univariate predictors of the number of hours worked were work history, satisfaction with job situation and financial situation LQoLP sub-scales, CAN proportion of social needs met and remission status. Multivariate regression analysis yielded a model in which work history and remission status where significant predictors of the number of hours employed $(P=0.001$ and $P<0.001$ respectively). Patients who had worked for more than 1 month were likely to work for more hours, as were those in remission between baseline and $T_{1}$ (Table 1).

\section{Early process predictors of entering competitive employment}

For all patients, univariate analysis indicated that service allocation (IPS $v$. vocational service), time from baseline to entry into the service, and patient- and professional-rated therapeutic relationship were each associated with employment status at the level appropriate for inclusion in the logistic regression $(P<0.1)$. There was a statistically significant correlation between patientand professional-rated therapeutic relationship scores at $T_{1}$ $(r=0.151)$, but this was not sufficiently large to necessitate the omission of one score from the logistic regression. Logistic regression generated a model in which service and higher HAS-v and HAS-p scores were significant predictors of entering employment (Table 2). The IPS patients were 2.6 times as likely to enter employment as vocational services patients $(\mathrm{OR}=2.57,95 \% \mathrm{CI}$ 1.18-5.64). The probability of working for at least 1 day was increased by $5 \%$ with a 1-point improvement in HAS-v score 


\begin{tabular}{|c|c|c|c|}
\hline Predictors & OR $(95 \% \mathrm{Cl})$ & Regression coefficient (s.e.) & $P$ \\
\hline \multicolumn{4}{|l|}{ Predictors of working for 1 day $(n=273)$} \\
\hline Work history & $2.42(1.42-4.12)$ & & 0.001 \\
\hline Clinical diagnosis (schizophrenia/ schizoaffective disorder v. bipolar disorder) & $1.22(0.58-2.55)$ & & 0.606 \\
\hline GAF-D score & $0.99(0.96-1.01)$ & & 0.213 \\
\hline HADS-D score & $0.99(0.93-1.06)$ & & 0.814 \\
\hline LQOLP-EU: satisfaction with job situation & $0.85(0.68-1.06)$ & & 0.144 \\
\hline LQOLP-EU: satisfaction with financial situation & $0.94(0.81-1.10)$ & & 0.458 \\
\hline Number of social needs (CAN) & $0.87(0.66-1.15)$ & & 0.317 \\
\hline Proportion of social needs met (CAN) & $0.99(0.98-1.00)$ & & 0.038 \\
\hline In remission between baseline and $T_{1}$ & $1.83(0.98-3.42)$ & & 0.058 \\
\hline \multicolumn{4}{|l|}{ Predictors of hours worked $(n=260)$} \\
\hline Work history & & $0.94(0.274)$ & 0.001 \\
\hline LQOLP-EU: satisfaction with job situation & & $0.18(0.110)$ & 0.102 \\
\hline LQOLP-EU: satisfaction with financial situation & & $0.03(0.081)$ & 0.711 \\
\hline Proportion of social needs met (CAN) & & $0.01(0.003)$ & 0.062 \\
\hline Remission & & $0.21(0.008)$ & $<0.001$ \\
\hline
\end{tabular}

$(\mathrm{OR}=1.05$, 95\% CI 1.02-1.09) and by 6\% with a 1-point improvement in HAS-p score (OR=1.06, 95\% CI 1.03-1.10).

In order to explore the relationship between service allocation and therapeutic relationship, a model was tested including service, patient- and professional-rated therapeutic relationship and their possible interactions. A significant interaction was found between service allocation and patient-rated therapeutic relationship, indicating that for patient ratings the effect of the relationship was limited to the IPS group. A 10-point increase in HAS-v score was associated with IPS patients having a 7\% higher probability of working for at least 1 day than vocational service patients $(\mathrm{OR}=1.07,95 \% \mathrm{CI} 1.00-1.14)$. There was no significant interaction between service allocation and professional-rated therapeutic relationship, indicating that the effect of the relationship held regardless of service.

When the analysis was repeated without service allocation (IPS $v$. vocational service), logistic regression generated a model in which only higher patient- and professional-rated therapeutic relationship scores were predictive of entering employment. A one-point improvement in HAS-v or HAS-p score was associated with a $6 \%$ increase in the probability of working for at least 1 day $(\mathrm{OR}=1.06,95 \%$ CI $1.02-1.09$ and $\mathrm{OR}=1.06,95 \%$ CI $1.03-1.10$ respectively).

A sensitivity analysis was conducted, testing therapeutic relationship against entering competitive employment excluding any patients who had entered employment before $T_{1}$. This again found therapeutic relationship (both HAS $-\mathrm{v}$ and HAS-p) to be significantly associated with working for at least 1 day.
Analysing time to service entry univariately, in order to include patients who had not entered the service by the 6-month follow-up, found that patients whose time to service entry was less than 2 months were significantly more likely to enter employment than those who had not entered the service by $T_{1}(\mathrm{OR}=1.9,95 \%$ CI 1.0-3.7, $P=0.049$ ).

\section{Early process predictors of time worked}

Early process predictors for number of hours worked included service allocation, patient- and professional-rated therapeutic relationship and time from baseline to service entry. Multivariate regression yielded a model in which service $(P=0.022)$, HAS $-\mathrm{v}$ score $(P=0.009)$ and HAS-p score $(P \leqslant 0.001)$ were significant. The IPS patients were likely to work more hours. There was also a statistically significant negative association between therapeutic relationship ratings and hours worked, but the parameter estimates were of negligible magnitude and therefore not clinically meaningful (Table 2).

When service allocation was omitted from the analyses, the predictive model of number of hours worked indicated that patients with better therapeutic relationships (higher HAS-v $(P=0.003)$ and HAS $-\mathrm{p}(P \leqslant 0.001)$ scores $)$ worked for fewer hours, but the parameter estimates were again of negligible magnitude. In this model, patients with shorter time from baseline to service entry $(P=0.027)$ tended to work for more hours.

When analysing time to service entry univariately, patients who entered the service within 2 months of baseline were likely to work for fewer hours $(P=0.012)$ than those who had not

\begin{tabular}{|c|c|c|c|}
\hline Predictors & OR $(95 \% \mathrm{Cl})$ & Regression coefficient (s.e.) & $P$ \\
\hline \multicolumn{4}{|l|}{ Predictors of working for 1 day $(n=202)$} \\
\hline Service (IPS v. vocational) & $2.57(1.18-5.64)$ & & 0.018 \\
\hline Time from baseline to entry into the service ( $<2$ months $v$. 2-6 months) & 0.00 & & 0.935 \\
\hline HAS-V total score & $1.05(1.02-1.09)$ & & 0.005 \\
\hline HAS-p total score & $1.06(1.03-1.10)$ & & 0.001 \\
\hline \multicolumn{4}{|l|}{ Predictors of hours worked ( $n=191)$} \\
\hline Service (IPS v. vocational) & & $0.96(0.042)$ & 0.022 \\
\hline Time from baseline to entry into the service ( $<2$ months $v .2-6$ months) & & $0.45(0.599)$ & 0.451 \\
\hline HAS-V total score & & $-0.05(0.018)$ & 0.009 \\
\hline HAS-p total score & & $-0.07(0.019)$ & $<0.001$ \\
\hline
\end{tabular}


entered it by $T_{1}$. Patients who entered the service between 2 and 6 months were more likely to work for more hours $(P=0.007)$ than those who had not entered it by $T_{1}$.

Additional analysis of time to first job largely confirmed the findings for our primary outcome, with previous work history, better therapeutic relationship and having fewer social needs met predicting getting the first job more quickly.

\section{Job tenure}

For the subgroup of patients who worked during the follow-up period, job tenure was univariately associated with the following patient characteristics: gender, work history prior to baseline, global disability, negative symptoms, satisfaction with safety and number of social needs met. Multivariate regression generated a model in which only satisfaction with safety was a significant predictor of job tenure, with patients with scores on lower satisfaction with safety being likely to stay longer in employment $(P=0.043)$. In the model of early process predictors, job tenure was univariately significantly associated with service allocation and time from baseline to service entry. Only service allocation was a significant predictor in the multivariate model $(P=0.010)$ (Table 3 ). Job tenure did not differ significantly between patients who entered the service within 2 months, between 2 and 6 months, or had not entered it by $T_{1}$.

\section{Service characteristic predictors of IPS effectiveness}

Values for the five service variables chosen to be possible sources of heterogeneity are detailed in Table 4, where data are presented on the difference in the variable between the IPS and vocational services at each centre.
Table 4 also presents the $Q$-statistics and associated $P$-values for the five variables. Contrast in IPS fidelity was a significant source of heterogeneity at the $10 \%$ significance level. As the contrast in IPS fidelity between the IPS and vocational services increased, the difference in effectiveness increased; thus, when there was a greater contrast in IPS fidelity, there was a greater effect size in favour of the IPS service (Fig. 1). As Fig. 1 shows, Sofia was the only outlier, as implementation of the IPS model was high in contrast to the low fidelity value. The other four variables were not associated with the IPS service effect size.

\section{Discussion}

\section{Patient predictors of employment outcomes}

Previous work history was the only patient characteristic predictive of all employment outcomes. Those who had worked for at least 1 month in the previous 5 years were more than twice as likely to enter competitive employment as those who had not; they obtained their first job more quickly and were also more likely to work for more hours. This confirms the findings of previous studies. ${ }^{8}$ Our measure of prior employment history was low (1 month's employment in 5 years), reflecting our replication of the original study, but nevertheless was strongly predictive.

In contrast with many studies, ${ }^{8}$ however, we did not find any association between age and employment outcomes; more unusually, no baseline clinical variables apart from remission were predictive. We thus did not replicate the finding that people with schizophrenia have worse employment outcomes than those with affective disorders. Nor did we replicate the evidence that negative rather than positive psychotic symptoms may be predictive of

\begin{tabular}{|lr|}
\hline Table 3 Predictors of job tenure. & Regression coefficient (s.e.) \\
\hline Variables in model $(n=121)$ & $P$ \\
\hline Patient characteristics model & $0.15(0.154)$ \\
$\quad$ Gender & $0.27(0.181)$ \\
Work history & $0.01(0.008)$ \\
GAF-D score & $-0.02(0.017)$ \\
PANSS-Negative & $-0.11(0.057)$ \\
LQOLP-EU: satisfaction with safety & $0.14(0.100)$ \\
Number of social needs met (CAN) & 0.134 \\
\hline Early process predictor model ( $n=122)$ & 0.150 \\
Service (IPS $v$. vocational) & 0.043 \\
Time from baseline to entry into the service (<2 months $v$. 2-6 months) & 0.151 \\
GAF-D, Global Assessment of Functioning - Disability; PANSS, Positive and Negative Syndrome Scale; LQoLP-EU, Lancashire Quality of Life Profile - European Version; CAN, & 0.65 (0.254) \\
\hline
\end{tabular}

\begin{tabular}{|c|c|c|c|c|c|c|}
\hline & IPS fidelity ${ }^{a, b}$ & $\begin{array}{c}\text { Proportion } \\
\text { entering service } \\
\text { within } 2 \text { months }\end{array}$ & $\begin{array}{l}\text { Named } \\
\text { keyworker } \\
\text { system }^{c}\end{array}$ & Case-load size ${ }^{c}$ & $\begin{array}{c}\text { Steps before job } \\
\text { search }^{c}\end{array}$ & Risk difference \\
\hline London & 33.50 & 76.0 & Yes & No & No & 0.32 \\
\hline Ulm & 28.00 & 100.0 & Yes & No & Yes & 0.12 \\
\hline Rimini & 35.00 & 73.1 & No & Yes & Yes & 0.31 \\
\hline Zurich & 36.50 & 76.9 & Yes & No & Yes & 0.38 \\
\hline Groningen & 28.25 & 19.3 & Yes & Yes & No & 0.08 \\
\hline Sofia & 30.25 & 18.5 & No & No & Yes & 0.41 \\
\hline Test of heterogeneity, $\mathrm{Q}(P)$ & $3.04(0.081)$ & $0.00(0.996)$ & $1.24(0.266)$ & $1.46(0.227)$ & $1.17(0.280)$ & \\
\hline
\end{tabular}




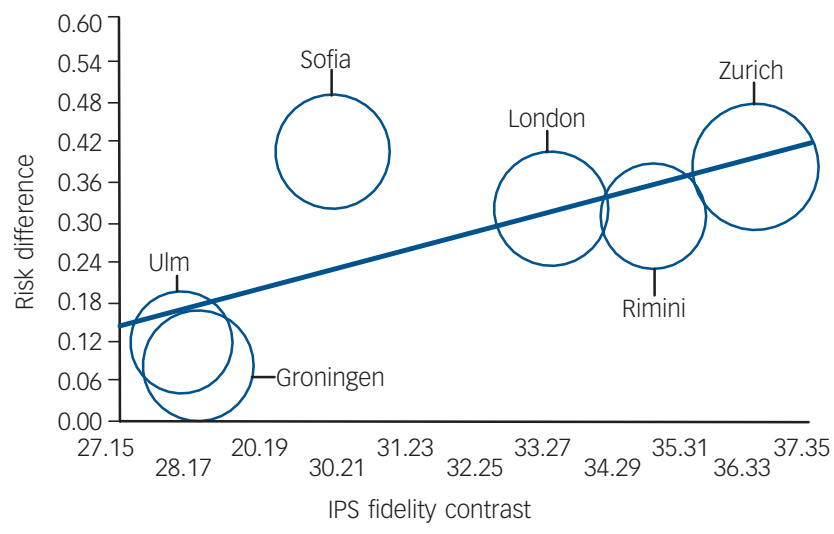

Fig. 1 Meta-regression of individual placement and support (IPS) fidelity contrast on risk difference. Data presented in Table 4 provide the coordinates of the bubble corresponding to each centre.

employment outcomes. ${ }^{25}$ This may have been because of the narrower clinical spread of our sample (only $20 \%$ had bipolar disorder and the sample was fairly homogeneous in terms of having a psychotic disorder for at least 2 years). For our sample, previous work experience and being in remission (which our study was the first to assess) clearly had more impact than any other patient factor, with being in remission for the first 6 months of the study being univariately associated with getting a job and predicting working more hours. Remission was not predictive of getting a job, however, when excluding from analysis all those who obtained jobs in the first 6 months of the study, suggesting that although being in remission in the first 6 months was associated with getting a job during that period, it was not predictive of getting a job subsequently.

Although our primary outcome, entering competitive employment, was operationalised using a low threshold (worked for 1 day), in practice, very few patients (two from each service) worked only for 1 day. Moreover, with respect to time worked, our findings largely replicated the findings relating to the primary outcome.

\section{Process predictors of employment outcomes}

Process variables have rarely been considered in studies of supported employment, beyond levels of IPS fidelity. Although we only considered early process predictors, measured at 6 months, all the IPS patients and two-thirds (67.3\%) of the vocational service patients had been taken into the services by then.

For those patients who had an IPS worker or named vocational worker, both patient- and professional-rated therapeutic relationship at $T_{1}$ were associated with working for at least 1 day, and this held even when those who found their jobs in the first 6 months of the study were excluded. For each increase of 5 points (out of 55) on the HAS at $T_{1}$, rated by either party, the likelihood of working increased by $30 \%$. For professionals' ratings of the relationship, this association held regardless of service. For patients' ratings, however, the association only operated in the IPS group. That the relationship with the vocational worker was predictive of getting a job is consistent with the evidence that a good therapeutic relationship is associated with a range of positive clinical outcomes, ${ }^{26}$ but this has not been previously tested in relation to vocational interventions and outcomes to our knowledge. The measure of relationship used here, the HAS, was designed for community-based mental healthcare and assesses the patient's and professional's view of the qualities offered by the professional, such as understanding and commitment to helping the patient. ${ }^{19}$ It has been validated against the more widely used Working Alliance Inventory. ${ }^{27,28}$ Its orientation is broadly clientcentred $^{29}$ and it was readily adapted for use in the context of the patient-vocational worker relationship.

The other process factors tested were not associated with entering competitive employment, even when service allocation was omitted from the analysis. Shorter time to service entry, however, was associated with working for more hours, although only in the model omitting the service allocation variable. This was because time to service entry was confounded by service type, with IPS services being more likely to take patients on more swiftly: in fact, all but two IPS patients were taken into the service by $T_{1}$, whereas the vocational service patients were more evenly spread between the three categories.

For the subgroup of patients who obtained jobs, job tenure was predicted only by satisfaction with safety at baseline, with patients who felt safer having shorter job tenure. This may suggest that those feeling safer personally had less motivation to work, although this did not affect their likelihood of getting a job at all. The relationship with the vocational worker was not related to job tenure, suggesting that it helped patients with obtaining a job, but did not affect their ability to maintain it.

\section{Motivation and dissatisfaction with life circumstances}

It is generally agreed that motivation to work has a significant influence on whether people with severe mental illness gain competitive employment and an initial screen for motivation is common practice. ${ }^{3}$ Macias et al, ${ }^{30}$ however, found that those with no interest in working did obtain work eventually and worked for as long as those who had had an initial interest, arguing against such an initial screen for motivation. Patients in the current study were screened for initial interest in work, so our cohorts did not exhibit a range of preferences. This is reflected in the fact that satisfaction with job situation at baseline, which effectively measured whether the patient was satisfied with not working, was not associated with employment outcomes. Nevertheless, there were several indications that dissatisfaction with aspects of their current circumstances, and thus a motivation to change them, may have been a factor in our study, although not tested systematically.

Having more of their social needs met at baseline made patients less likely to get a job. Thus, being more satisfied with social and intimate relationships seems to have given them less incentive to seek work. Similarly, having one more service need met (needs for information, transport, access to telephone and benefits), likely to reflect satisfaction with benefits, also doubled the likelihood of a patient withdrawing from the vocational service. Satisfaction with personal or neighbourhood safety had a comparable impact on job tenure, with those feeling less safe being more likely to hold onto their job for longer.

Findings on time to service entry, though based on univariate analysis only, also suggest an impact of motivation. These findings were driven by the vocational service patients, who entered the service over a longer period of time than did the IPS patients. Those taken into the service between 2 and 6 months after baseline worked for more hours than those not in the service at $T_{1}$, but those taken in even more swiftly actually worked for fewer hours. It may be that those taken into the service very swiftly had no opportunity to lose (or demonstrate) motivation, so although they were likely to get a job they eventually worked for fewer 
hours; those who waited longer to be taken into the service but did then engage with it, thus having to maintain their motivation over time, subsequently worked for more hours.

Although the function of employment as therapeutic or empowering for users of mental health services has been often suggested, ${ }^{31,32}$ our findings provide some evidence that even within a group identifying themselves as wishing to work, specific personal circumstances and experiences of clinical services may actually be demotivating in seeking competitive employment.

\section{Service characteristics and IPS effectiveness}

Prospective meta-analysis methodology has been applied to the analysis of a similar multicentre trial of a complex intervention by Banks et $a l^{33}$ and was also used in the present study to explore how variation in effectiveness of IPS can be explained partially by socio-economic factors. ${ }^{7}$ The five centre-level service characteristics tested here were all expressed as the difference between the IPS and the vocational service at each international centre. The impact of a centre's IPS service having particularly high IPS fidelity might thus be counterbalanced by its vocational service being particularly close to the IPS service. Only IPS fidelity contrast explained the heterogeneity between centres with regard to the effectiveness of the IPS model, and this was the only trend $(P=0.081)$. This is comparable to the findings of several studies that IPS fidelity is associated with its effectiveness. ${ }^{34,35}$ The nature of the meta-analytic technique precluded also testing IPS fidelity per se.

\section{Beyond fidelity}

Although the importance of fidelity to the IPS model has been demonstrated in a number of studies, ${ }^{35-37}$ it does not account for all the variance in outcome in IPS studies. ${ }^{38}$ Drake et al ${ }^{38}$ have therefore argued that other features need to be considered, such as professional skills. The present study has begun to fill this gap in the literature by analysing process variables. Our finding that therapeutic relationship predicted getting a job suggests that building a relationship with the patient is one of the key skills involved in vocational services, with a demonstrable effect on vocational outcome. It is standard paractice for IPS workers to be deliberately recruited from professionals without prior mental health experience ${ }^{39}$ and anecdotally this lack of experience of the patient group was an initial hurdle for the professionals involved. Our findings suggest that targeting relational skills for working with this patient group would be a valuable focus for all vocational interventions.

\section{Limitations}

The study was powered on the comparison of IPS with vocational services, ${ }^{7}$ although the sample was sufficiently large for the analyses presented here. However, the number of predictors selected for inclusion in the multiple regression on the basis of univariate pre-testing means that some associations reported as statistically significant may, in fact, be spurious.

The prospective meta-analysis technique allowed inclusion of only five variables (number of centres minus one). This limited the number of variables we could explore, although it did allow for a more focused, hypothesis-driven analysis. In addition, early process variables were collected at $T_{1}$ rather than at a fixed interval from each individual patient's service entry.

The fact that the analysis of early process predictors had to be conducted with the subgroup of patients who could provide HAS data means that the impact of delay to entering the service on the whole patient group, including those who did not enter the service at all, could only be considered univariately. Patients who did not enter the service at all were not significantly less likely to work for at least 1 day, however. ${ }^{7}$ Nor was delay entering the service found to be associated with the effectiveness of the IPS model when considered at the service level in the prospective meta-analysis.

Our findings closely parallel those of previous studies and therefore should be widely generalisable, but the motivation and focus that inevitably comes from participation in a research study cannot be ignored. Effect sizes are likely to be more modest in routine practice.

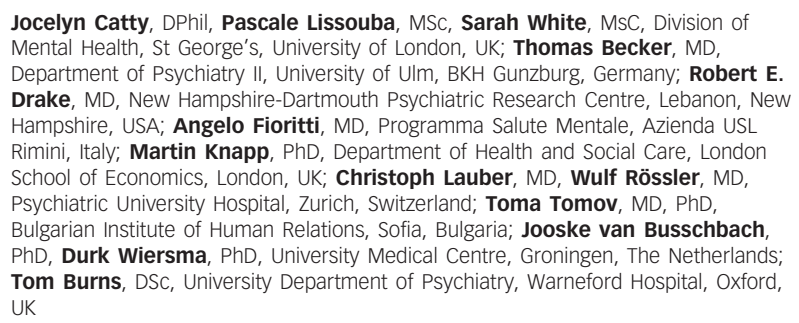

Correspondence: Tom Burns, University Department of Psychiatry, Warneford Hospital, Oxford OX3 7JX, UK. Email: Tom.Burns@psych.ox.ac.uk

First received 11 Jun 2007, final revision 13 Nov 2007, accepted 12 Dec 2007

\section{Acknowledgements}

T.B. designed the study with W.R. and A.F.; it was run by T.B. and J.C. All authors were involved in the conduct of the study, interpreting the results and in revising and correcting the paper, which was drafted by J.C. and T.B. The analyses were led by S.W. All authors read and approved the final version of the manuscript.

Members of the Enhancing the Quality fo Life and Independence of Persons Disabled by Severe Mental Illness through Supported Employment (EQOLISE) Group are as follows: Tom Burns, Jocelyn Catty, Connie Geyer, Marsha Koletsi, Pascale Lissouba, Miles Rinaldi, Sarah White (London), Thomas Becker, Ulrike Ehiosun, Rana Kalkan, Reinhold Kilian (Ulm), Angelo Fioritti, Denise Manchisi (Rimini), Astrid Niersman, Jooske van Busschbach, Durk Wiersma (Groningen), Christoph Lauber, Wulf Rössler, Ingeborg Warnke (Zurich), Dimitar (LSE).

This study was funded by a grant from the European Union, Quality of Life and Management of Living Resources Programme (QLRT 2001-00683). Thanks are due to Greg McHugo for methodological advice, to Deborah R. Becker and Miles Rinaldi for training the IPS Workers, and to the IPS Workers themselves: Alison Lewis (London), Wulf Dorn and Eva Marischka (UIm), Donato Piegari (Rimini), Bettina Bartsch and Patric Meyer (Zurich), Anne Mieke Epema, Laureen Jansen and Bea Hummel (Groningen), and Petar Karaginev (Sofia).

\section{References}

1 Marwaha S, Johnson S, Bebbington $\mathrm{P}$, Stafford $\mathrm{M}$, Angermeyer $\mathrm{MC}$, Brugha $\mathrm{T}$, Azorin JM, Kilian R, Hansen K, Toumi M. Rates and correlates of employment in people with schizophrenia in the UK, France and Germany. Br J Psychiatry 2007; 191: 30-7.

2 Crowther RE, Marshall M, Bond GR, Huxley P. Helping people with severe mental illness to obtain work: systematic review. BMJ 2001; 322: 204-8.

3 Drake RE, McHugo GJ, Bebout RR, Becker DR, Harris M, Bond GR, Quimby E. A randomized clinical trial of supported employment for inner-city patients with severe mental disorders. Arch Gen Psychiatry 1999; 56: 627-33.

4 Lehman AF, Goldberg R, Dixon LB, McNary S, Postrado L, Hackman A, McDonnell K. Improving employment outcomes for persons with severe mental illnesses. Arch Gen Psychiatry 2002; 59: 165-72.

5 Mueser KT, Clark RE, Haines M, Drake RE, McHugo GJ, Bond GR, Essock SM, Becker DR, Wolfe R, Swain K. The Hartford study of supported employment for persons with severe mental illness. J Consult Clin Psychol 2004; 72: 47990.

6 Latimer EA, Lecomte T, Becker DR, Drake RE, Duclos I, Piat M, Lahaie N, StPierre MS, Therrien $\mathrm{C}$, Xie H. Generalisability of the individual placement and support model of supported employment: results of a Canadian randomised controlled trial. Br J Psychiatry 2006; 189: 65-73.

7 Burns T, Catty J, Becker T, Drake RE, Fioritti A, Knapp M, Lauber C, Rössler W, Tomov T, van Busschbach J, White S, Wiersma D; on behalf of the EQOLISE Group. The effectiveness of supported employment for people with severe mental illness: a randomised controlled trial. Lancet 2007; 370: 1146-52. 
8 Wewiorski NJ, Fabian ES. Association between demographic and diagnostic factors and employment outcomes for people with psychiatric disabilities: a synthesis of recent research. Ment Health Serv Res 2004; 6: 9-21.

9 Endicott J, Spitzer RL, Fleiss JL, Cohen J. The global assessment scale. A procedure for measuring overall severity of psychiatric disturbance. Arch Gen Psychiatry 1976; 33: 766-71.

10 Kay SR, Fiszbein A, Opler LA. The positive and negative syndrome scale (PANSS) for schizophrenia. Schizophr Bull 1987; 13: 261-76.

11 Zigmond AS, Snaith RP. The hospital anxiety and depression scale. Acta Psychiatr Scand 1983; 67: 361-70.

12 Wiersma D, de Jong A, Kraaijkamp HJM, Ormel J. The Groningen Social Disabilities Schedule, Second Version (GSDS-II): Manual and Interview Schedule. University of Groningen, 1990.

13 Wiersma D, de Jong A, Ormel J. The Groningen Social Disabilities Schedule: development, relationship with the ICIDH and psychometic properties. Int $J$ Rehabil Res 1988; 11: 213-24.

14 Oliver JP, Huxley PJ, Priebe S, Kaiser W. Measuring the quality of life of severely mentally ill people using the Lancashire Quality of Life Profile. Soc Psychiatry Psychiatr Epidemiol 1997; 32: 76-83.

15 Gaite L, Vázquez-Barquero JL, Arrizabalaga AA, Schene AH, Welcher B, Thornicroft G, Ruggeri M, Vázquez-Bourgon $E$, Pérez Retuerto $M$, Leese $M$ Epsilon Study Group. Quality of life in schizophrenia: development, reliability and internal consistency of the Lancashire Quality of Life Profile - European Version. EPSILON Study 8. Br J Psychiatry 2000; 177 (suppl 39): s49-54.

16 Rosenberg M. Society and the Adolescent Self-Image. Princeton University Press, 1969.

17 Phelan M, Slade M, Thornicroft G, Dunn G, Holloway F, Wykes T, Strathdee G, Loftus L, McCrone P, Hayward P. The Camberwell Assessment of Need: the validity and reliability of an instrument to assess the needs of people with severe mental illness. Br J Psychiatry 1995; 167: 589-95.

18 Mccrone $P$, Leese $M$, Thornicroft $G$, Schene $A H$, Knudsen $H C$, Vázquez Barquero JL, Lasalvia A, Padfield S, White IR, Griffiths G, Epsilon Study Group. Reliability of the Camberwell Assessment of Need - European Version. EPSILON Study 6. Br J Psychiatry 2000; 177 (suppl 39): s34-40.

19 Priebe $S$, Gruyters $T$. The role of the helping alliance in psychiatric community care. A prospective study. J NerV Ment Dis 1993; 181: 552-7.

20 McGuffin P, Farmer A, Harvey I. A polydiagnostic application of operational criteria in studies of psychotic illness. Development and reliability of the OPCRIT system. Arch Gen Psychiatry 1991; 48: 764-70.

21 Bond G, Becker DR, Drake RE. A fidelity scale for the Individual Placement and Support model of supported employment. Rehabil Couns Bull 1997; 40 265-84

22 van Os J, Burns T, Cavallaro R, Leucht S, Peuskens J, Helldin L, Bernardo M Arango C, Fleischhacker W, Lachaux B, Kane JM. Standardized remission criteria in schizophrenia. Acta Psychiatr Scand 2006; 113: 91-5.
23 Gardner W, Mulvey EP, Shaw EC. Regression analyses of counts and rates: Poisson, overdispersed Poisson, and negative binomial models. Psychol Bull 1995: 118: 392-404.

24 Hall DB. Zero-inflated Poisson and binomial regression with random effects: a case study. Biometrics 2000; 56: 1030-9.

25 Green MF. What are the functional consequences of neurocognitive deficits in schizophrenia? Am J Psychiatry 1996; 153: 321-30.

26 McGuire-Snieckus R, McCabe R, Catty J, Hansson L, Priebe S. A new scale to assess the therapeutic relationship in community mental health care: STAR. Psychol Med 2007; 37: 85-95.

27 Hovarth A, Greenberg L. Development and validation of the Working Alliance Inventory. J Couns Psychol 1989; 36: 223-33.

28 Bale R, Catty J, Watt H, Greenwood N, Burns T. Measures of the therapeutic relationship in severe psychotic illness: a comparison of two scales. Int I SOC Psychiatry 2006; 52: 256-66.

29 Catty J, Winfield $\mathrm{H}$, Clement S. The therapeutic relationship in secondary mental health care: a conceptual review of measures. Acta Psychiatr Scand 2007; 116: 238-52.

30 Macias C, DeCarlo L, Wang Q, Frey J, Barreira P. Work interest as a predictor of competitive employment: policy implications for psychiatric rehabilitation. Adm Policy Ment Health 2001; 28: 279-97.

31 Harding CM, Strauss JS, Hafez $\mathrm{H}$, Lieberman PB. Work and mental illness. I. Toward an integration of the rehabilitation process. J Nerv Ment Dis 1987; 175: $317-26$.

32 Rogers J. Work is key to recovery. Psychosoc Rehabil J 1995; 18: 5-10.

33 Banks S, McHugo GJ, Williams VF, Drake RE, Shinn M. A prospective metaanalytic approach to the analysis of multi-site data. New Dir Eval 2002; 94 $45-59$.

34 Drake RE, McHugo GJ, Becker DR, Anthony WA, Clark RE. The New Hampshire study of supported employment for people with severe mental illness. J Consult Clin Psychol 1996; 64: 391-9.

35 Becker DR, Xie H, McHugo GJ, Halliday J, Martinez RA. What predicts supported employment program outcomes? Community Ment Health J 2006; 42: 303-13.

36 Becker DR, Smith J, Tanzman B, Drake RE, Tremblay T. Fidelity of supported employment programs and employment outcomes. Psychiatr Serv 2001; 52: 834-6.

37 McGrew JH, Griss ME. Concurrent and predictive validity of two scales to assess the fidelity of implementation of supported employment. Psychiatr Rehabil J 2005; 29: 41-7.

38 Drake RE, Bond GR, Rapp C. Explaining the variance within supported employment programs: comment on "What predicts supported employment outcomes?". Community Ment Health J 2006; 42: 315-8.

39 Becker DR, Drake RE. A Working Life for People with Severe Mental IIIness. Oxford University Press, 2003. 